\title{
Prevalence of Streptococcus pneumoniae serotype 6C among invasive and carriage isolates in metropolitan Salvador, Brazil, from 1996 to 2007
}

\author{
Leila C. Campos ${ }^{\mathrm{a}, \mathrm{b}}$, Maria da Gloria S. Carvalho ${ }^{\mathrm{c}}$, Bernard W. Beall ${ }^{\mathrm{c}}$, Soraia M. Cordeiro ${ }^{\mathrm{a}}$, \\ Daniele Takahashi ${ }^{\mathrm{a}}$, Mitermayer G. Reis ${ }^{\mathrm{a}}$, Albert I. Ko ${ }^{\mathrm{a}, \mathrm{d}}$, Joice N. Reis ${ }^{\mathrm{a}, \mathrm{e}, *}$ \\ ${ }^{a}$ Centro de Pesquisas Gonçalo Moniz, Fundação Oswaldo Cruz, Salvador, BA 40296-710, Brazil \\ ${ }^{\mathrm{b}}$ Instituto Oswaldo Cruz, Fundação Oswaldo Cruz, Rio de Janeiro, RJ 21045-900, Brazil \\ ${ }^{\mathrm{c}}$ Respiratory Diseases Branch, Centers for Disease Control and Prevention, Atlanta, GA 30333, USA \\ ${ }^{\mathrm{d}}$ Division of Infectious Diseases, Department of Medicine, Weill Medical College of Cornell University, New York, NY 10021, USA \\ ${ }^{\mathrm{e}}$ Faculdade de Farmácia, Universidade Federal da Bahia, Salvador, BA 40170-115, Brazil \\ Received 20 April 2009; accepted 19 June 2009
}

\begin{abstract}
The newly described Streptococcus pneumoniae serotype 6C accounted for 2.3\% (16/709) of meningitis cases and 3.2\% (3/95) of nasopharyngeal isolates from healthy individuals in Brazil. The strains were multidrug resistant (18.8\%) and genetically diverse. Despite low serotype $6 \mathrm{C}$ prevalence, continuous surveillance is necessary to guide vaccine strategies.
\end{abstract}

(C) 2009 Elsevier Inc. All rights reserved.

Keywords: Streptococcus pneumoniae; Serotype 6C; Epidemiology; Meningitis; Carriage

\section{Introduction}

Streptococcus pneumoniae is a significant cause of morbidity and mortality especially among children $<2$ years old and the elderly (World Health Organization [WHO], 2007). The antiphagocytic polysaccharide capsule is the major virulence determinant of $S$. pneumoniae (Kadioglu et al., 2008). Of the 91 known capsular serotypes (Park et al., 2007b), approximately 20 are associated with $>80 \%$ of invasive pneumococcal disease (IPD) (Hausdorff et al., 2000).

The serotypes $6 \mathrm{C}$ and $6 \mathrm{~A}$ biosynthetic loci are identical except for the presence of different $w c i \mathrm{~N}$ genes that encode distinct glycosyl transferases (Park et al., 2007a). The 2 serotypes are not resolved by classic quelling serotyping (Park et al., 2007a). Classically serotyped 6A pneumococci (CS6As) are associated with nasopharyngeal (NP) carriage and IPD in all ages (du Plessis et al., 2008; Granat et al., 2007; Reis et al., 2008).

\footnotetext{
* Corresponding author. Centro de Pesquisas Gonçalo Moniz, Fundação Oswaldo Cruz/MS, Rua Waldemar Falcão 121, Salvador, BA 40296-710, Brazil. Tel.: +55-71-3176-2302; fax: +55-71-3176-2281.

E-mail address: joice@ufba.br (J.N. Reis).
}

The currently available 7 -valent pneumococcal conjugate vaccine (PCV7) has been highly effective against the 7 serotypes that were predominant in children before its implementation in the United States (CDC, 2008; WHO, 2007). PCV7 contains serotype $6 \mathrm{~B}$ and cross-protects against $6 \mathrm{~A}$; however, recent surveillance data indicates that PCV7 is ineffective against serotype 6C (Carvalho et al., 2009; Park et al., 2008).

We show here the prevalence of serotype $6 \mathrm{C}$ within a well-defined collection of CS6As collected in Brazil from meningitis cases and NP carriage.

Antimicrobial susceptibility testing used broth microdilution. MICs of 10 key antibiotics were determined using year 2007 Clinical and Laboratory Standards Institute guidelines (CLSI, 2007). Intermediate penicillin resistance (MICs of $0.12-1.0 \mu \mathrm{g} / \mathrm{mL}$ ) or full penicillin resistance (MICs $\geq 2.0$ $\mu \mathrm{g} / \mathrm{mL}$ ) was considered penicillin nonsusceptible.

CS6As were subtyped using a triplex polymerase chain reaction (PCR) reaction that detects cps A (conserved capsular biosynthetic locus; $160 \mathrm{bp}$ ), serogroup 6 (250 bp), and the $6 \mathrm{C}$-specific gene $w c i N_{6 \mathrm{C}}(727 \mathrm{bp}$ ) (Carvalho et al., 2009). DNA extraction and PCR were performed as described (http://www.cdc.gov/ncidod/biotech/strep/pcr. 
Table 1

Characteristics of meningitis cases caused by $S$. pneumoniae serotypes 6A and 6C in Salvador, Brazil, 1996 to 2007

\begin{tabular}{|c|c|c|c|}
\hline \multirow[t]{2}{*}{ Characteristic } & \multicolumn{2}{|c|}{ No. of isolates (\%) } & \multirow[t]{2}{*}{$P$} \\
\hline & $6 \mathrm{~A}(n=31)$ & $6 \mathrm{C}(n=16)^{\mathrm{a}}$ & \\
\hline \multicolumn{4}{|l|}{ Age } \\
\hline$<5$ years & $15 / 31(48.4)$ & $4 / 15(26.7)$ & \multirow{6}{*}{0.02} \\
\hline$\geq 5$ years & $16 / 31(51.6)$ & $11 / 15(73.3)$ & \\
\hline Male gender & $17 / 31(54.8)$ & $11 / 15(73.3)$ & \\
\hline $\begin{array}{l}\text { Case fatality rate } \\
\text { (no. of deaths } / \text { no. of cases) }\end{array}$ & $8 / 29^{\mathrm{b}}(27.6)$ & $0 / 15(0.0)$ & \\
\hline Penicillin nonsusceptible & $3 / 31(9.7)$ & $1 / 16(6.3)$ & \\
\hline Sxt nonsusceptible & $17 / 31(54.8)$ & $12 / 16(75.0)$ & \\
\hline
\end{tabular}

htm). Pulsed-field gel electrophoresis (PFGE) of chromosomal SmaI (Sigma, St. Louis, MO) digests was performed as described (McEllistrem et al., 2000; Tenover et al., 1995). Multilocus sequence typing was performed (Enright and Spratt, 1998) on 8 isolates representing the 2 PFGE clusters and 3 PFGE outliers.

CS6As consisting of 47 (6.6\%) cerebrospinal fluid (CSF) isolates from a collection of 709 pneumococci identified in metropolitan Salvador, Brazil, during 12 years (1996-2007) of bacterial meningitis surveillance and $9 \mathrm{NP}$ isolates (Reis et al., 2008) were tested by triplex PCR to resolve serotypes 6C and serotype 6A. Of 56 CS6As tested, 16/47 (34\%) from meningitis patients were PCR positive for $w c i N_{6 \mathrm{C}}$, indicating that $4.4 \%(31 / 709)$ and $2.3 \%(16 / 709)$ of meningitis cases were caused by serotypes $6 \mathrm{~A}$ and $6 \mathrm{C}$, respectively. In addition, $6 \mathrm{~A}$ and $6 \mathrm{C}$ represented $6.4 \%$ and $3.2 \%$ (3/95) of carriage isolates, respectively. Low prevalences of serotype $6 \mathrm{C}$ disease and colonization have also been observed in South Africa (du Plessis et al., 2008) and Portugal (Nunes et al., 2009).

There were no significant differences between serotypes $6 \mathrm{~A}$ and $6 \mathrm{C}$ with respect to ages and genders of meningitis patients. Serotype $6 \mathrm{C}$ meningitis cases were associated with a significantly lower case fatality rate than serotype $6 \mathrm{~A}$ cases ( $0 \%$ [ 0 of 15 cases] versus $28 \%$ [ 8 of 29 cases], respectively, $P=0.02$ ) (Table 1). These findings are in contrast to observations in South Africa (du Plessis et al., 2008) where significantly different case fatality rates between serotypes $6 \mathrm{~A}$ and $6 \mathrm{C}$ were not observed.

Table 2 lists the antibiotic susceptibility of all serotype $6 \mathrm{C}$ isolates identified. Among meningitis case CS6As, 71\% (22 of 31 ) of $6 \mathrm{~A}$ and $81.3 \%$ (13 of 16) of $6 \mathrm{C}$ were nonsusceptible to at least one antibiotic. Similar proportions of serotype $6 \mathrm{~A}$ and $6 \mathrm{C}$ meningitis isolates were nonsusceptible to penicillin or trimethoprim/sulfamethoxazole (Sxt). Among 6C isolates, $6.3 \%$ ( 1 of 16$)$ and $75 \%$ (12 of 16$)$ were nonsusceptible to penicillin and Sxt, respectively, whereas $10 \%$ of $6 \mathrm{~A}$ isolates were penicillin nonsusceptible and $55 \%$ were Sxt nonsusceptible. The high frequency of Sxt resistance among meningitis CS6As reflects widespread use of this drug in Brazil (Reis et al., 2008). Multidrug resistance was found among $19.4 \%$ (6 of 31 ) and $18.8 \%$ (3 of 16) of serotype $6 \mathrm{~A}$ and $6 \mathrm{C}$ meningitis isolates, respectively. Of CS6As obtained during a NP carriage study of a healthy population in Salvador (Reis et al., 2008), 2/3 (67\%) 6C isolates and 1/6 $6 \mathrm{~A}(16.7 \%)$ isolates were multidrug resistant.

PFGE of serotype 6C chromosomal digests revealed 2 clusters and 6 outlier patterns (Fig. 1). Cluster I (black stars) represented 8 meningitis isolates, whereas cluster II (white stars) represented 2 meningitis isolates and 3 NP carriage isolates. PFGE cluster I isolates were associated with 2 newly identified sequence types (STs), ST3929 and ST3930, which differed by only 2 loci. ST3930 differed by only 1 or 2 loci from 5 CS6As (NP and lower respiratory tract isolates) recovered in Finland, the United States, and Poland (http:// www.mlst.net). PFGE cluster II isolates were associated with ST812, which is a single locus variant (SLV) of ST753 from a CS6A meningitis isolate recovered in Brazil and a double locus variant of ST2789 from a type 6C carriage isolate

Table 2

Antimicrobial susceptibilities of S. pneumoniae serotype 6C isolates in metropolitan Salvador, Brazil, from 1996 to $2007^{\mathrm{a}}$

\begin{tabular}{|c|c|c|c|c|c|c|}
\hline \multirow{2}{*}{$\begin{array}{l}\text { Antimicrobial } \\
\text { agents }\end{array}$} & \multicolumn{3}{|l|}{$\operatorname{MIC}(\mu \mathrm{g} / \mathrm{mL})^{\mathrm{b}}$} & \multicolumn{3}{|c|}{ No. $(\%)$ of isolates ${ }^{c}$} \\
\hline & Range & $\mathrm{MIC}_{50}$ & $\mathrm{MIC}_{90}$ & $\mathrm{~S}$ & I & $\mathrm{R}$ \\
\hline Cefotaxime & $0.016-64$ & 0.016 & 0.031 & $19(100)$ & - & - \\
\hline Chloramphenicol & $0.016-64$ & 2.0 & 4.0 & $17(89.5)$ & NA & $2(10.5)$ \\
\hline Clindamycin & $0.016-64$ & 0.031 & 0.062 & $19(100)$ & - & - \\
\hline Erythromycin & $0.016-64$ & 0.062 & 0.25 & $18(94.7)$ & - & $1(5.3)$ \\
\hline Ofloxacin & $0.016-64$ & 1.0 & 2.0 & $19(100)$ & - & - \\
\hline Penicillin & $0.016-64$ & 0.031 & 0.062 & $18(94.7)$ & $1(5.3)$ & - \\
\hline Rifampicin & $0.016-64$ & 0.031 & 0.062 & $19(100)$ & - & - \\
\hline Tetracycline & $0.016-64$ & 0.5 & 8.0 & $15(78.9)$ & - & $4(21.1)$ \\
\hline Sxt & $0.0625 / 1.1875-32 / 608$ & 1.0 & 2.0 & $6(31.6)$ & $11(57.9)$ & $2(10.5)$ \\
\hline Vancomycin & $0.016-64$ & 0.5 & 0.5 & $19(100)$ & NA & - \\
\hline
\end{tabular}

$\mathrm{S}=$ susceptible; $\mathrm{I}=$ intermediate; $\mathrm{R}=$ resistant; $\mathrm{NA}=$ not applicable; - = no isolates were identified.

${ }^{\text {a }}$ A total of 19 isolates were tested (16 isolates from meningitis patients and 3 isolates from NP carriages).

${ }^{b}$ MICs were determined by the broth microdilution method (CLSI, 2007). MIC $_{50}$ and MIC $_{90}$ concentrations at which the growth of $50 \%$ and $90 \%$, respectively, of the isolates is inhibited.

c The breakpoints used to define susceptibility categories were those recommended by the Clinical Laboratory Standards Institute (CLSI, 2007). 


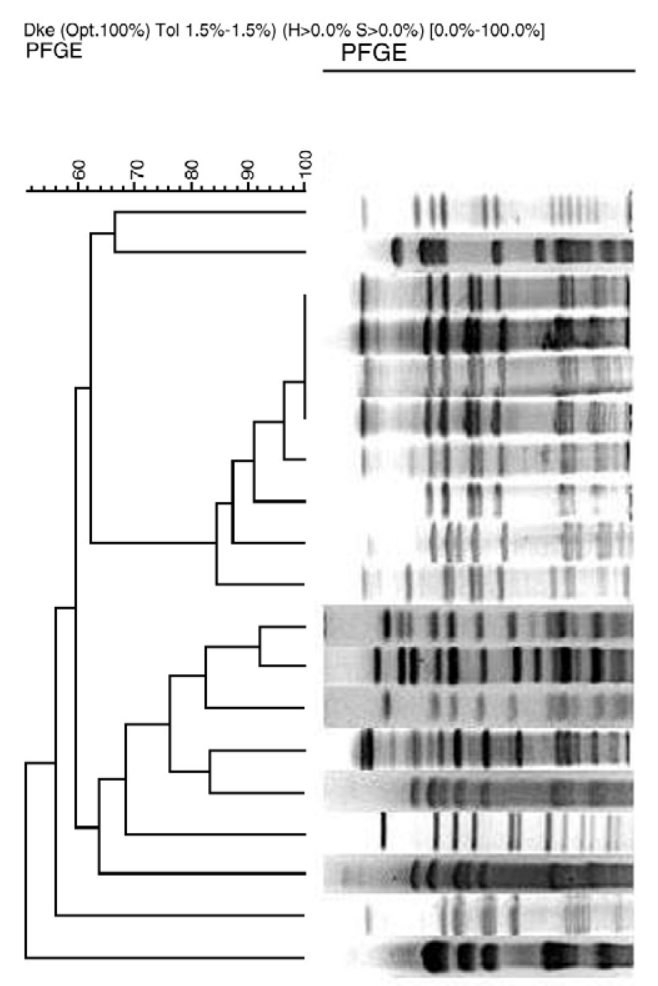

\begin{tabular}{|c|c|c|c|c|c|}
\hline 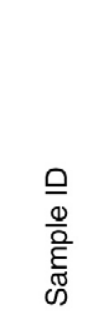 & 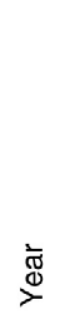 & 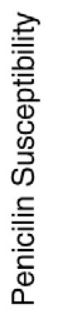 & 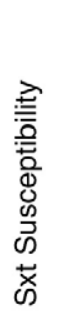 & 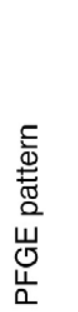 & $\stackrel{\llcorner}{\stackrel{E}{\Sigma}}$ \\
\hline $480 \mathrm{~A}$ & 2003 & $\mathrm{~S}$ & NS & $\mathrm{DA}$ & \\
\hline $411 \mathrm{~A}$ & 2001 & $S$ & $S$ & $\mathrm{DE}$ & \\
\hline$\star 151 \mathrm{~A}$ & 1997 & $\mathrm{~s}$ & $\mathrm{~S}$ & ER1 & \\
\hline$\star 2 A$ & 1996 & $S$ & NS & ER1 & ST 3930 \\
\hline$\star 708 \mathrm{~A}$ & 2007 & $\mathrm{~s}$ & NS & ER1 & \\
\hline$\star 511 \mathrm{~A}$ & 2003 & $S$ & NS & ER1 & \\
\hline$\star 93 \mathrm{~A}$ & 1997 & $\mathrm{~s}$ & NS & ER2 & \\
\hline$\star 510 \mathrm{~A}$ & 2003 & $\mathrm{~S}$ & NS & ER3 & \\
\hline$\star 565 \mathrm{~A}$ & 2004 & $\mathrm{~S}$ & NS & ER4 & ST 3930 \\
\hline$\star 244 \mathrm{~A}$ & 1999 & $S$ & $S$ & ER5 & ST 3929 \\
\hline$\Rightarrow 30220$ & 2000 & $\mathrm{~S}$ & NS & N2 & \\
\hline$\dot{*} 6052$ & 2000 & $\mathrm{~S}$ & $S$ & N3 & ST 812 \\
\hline$\Rightarrow 30219$ & 2000 & $S$ & NS & N1 & ST 812 \\
\hline$\Rightarrow 286 \mathrm{~A}$ & 1999 & $\mathrm{~S}$ & NS & N4 & ST 812 \\
\hline$\Rightarrow 119 \mathrm{~A}$ & 1997 & $S$ & NS & N5 & \\
\hline $528 \mathrm{~A}$ & 2003 & NS & NS & $\mathrm{FV}$ & ST 2717 \\
\hline $395 \mathrm{~A}$ & 2001 & $\mathrm{~S}$ & $S$ & ET & \\
\hline $555 \mathrm{~A}$ & 2004 & $\mathrm{~S}$ & NS & LC & \\
\hline $412 \mathrm{~A}$ & 2001 & $S$ & NS & $\mathrm{JR}$ & ST 743 \\
\hline
\end{tabular}

Fig. 1. PFGE analysis showing serotype 6C isolates recovered from meningitis cases and carriage. Cluster I (black stars) comprised 8 meningitis isolates (nos. 151A, 2A, 708A, 511A, 93A, 510A, 565A, and 244A) belonging to ST3930; cluster II (white stars), comprised 2 meningitis isolates (nos. 286A and 199A) and 3 6C NP carriage isolates (nos. 30220, 6052, and 30219) belonging to ST812. The other 6 isolates are genetic outliers as judged by PFGE relationships. S = susceptible; NS = nonsusceptible.

recovered in Portugal (Nunes et al., 2009). The PFGE outlier correlated with ST2777, which was also from a type 6C CSF isolate recovered in Brazil (http://www.mlst.net). It is interesting that ST2777 is an SLV of ST338 from the clone Colombia $^{23 \mathrm{~F}}-26$ that is associated with antibiotic-nonsusceptible $23 \mathrm{~F}$ and $23 \mathrm{~A}$ isolates (Pai et al., 2005). The final PFGE outlier (ST743) was previously associated with serotype 34 meningitis and NP isolates (http://www.mlst. net). Overall, these data are consistent with other studies indicating both a high degree of genetic diversity within serotype $6 \mathrm{C}$ and its long-term existence within the species (Jacobs et al., 2009; Nunes et al., 2009; Park et al., 2007a). In our study, the first $6 \mathrm{C}$ isolate identified was isolated in March 1996 (strain no. 2A). Vaccine pressure could potentially select for the emergence of preexisting $6 \mathrm{C}$ clones and $6 \mathrm{C}$ variants that arise through serotype switching.

In Brazil, PCV7 will probably be implemented within the next several years in young children (Brasil, 2008). Although PCV7 does not protect against $6 \mathrm{C}$ disease (Carvalho et al., 2009; Park et al., 2008), we found that the prevalence of serotype 6C among meningitis isolates is low (2.3\%). Nonetheless, serotype replacement in disease incidence is a concern, where non-PCV7 serotypes such as type $6 \mathrm{C}$ could possibly emerge as important pathogens due to removal of vaccine serotype strain competitors from the NP reservoir (Hicks et al., 2007; Moore et al., 2008). A slight increase of 6C IPD has been documented in the post-PCV7 era among adults in the United States, where 6C has become the prevalent serogroup 6 serotype (Carvalho et al., 2009; Moore et al., 2008; Park et al., 2008). We emphasize that these data showing a predominance of $6 \mathrm{C}$ from the United States primarily indicate high efficacy of PCV7 against serotypes $6 \mathrm{~A}$ and $6 \mathrm{~B}$ rather than $6 \mathrm{C}$ emergence. Continuous pneumococcal serotype surveillance is necessary to evaluate the impact and suitability of current conjugate vaccines in developing countries such as Brazil.

\section{Acknowledgments}

The authors thank Dr Marise D. Asensi (Instituto Oswaldo Cruz, FIOCRUZ, Rio de Janeiro, Brazil) for her help in the PFGE performance. They are grateful for the global pneumococcal multilocus sequence typing database (Imperial College London, funded by the Wellcome Trust). This study was supported by grants from the Brazilian National Research Council (CNPq - 491345/2005-4 and 
478685/2007-6), Research Support Foundation for the State of Bahia (FAPESB_-1431040054051), and Fogarty International Center of the National Institute of Health, USA (R01 TW007303 and D43TW00919).

\section{References}

Brasil. Ministério da Saúde. Secretaria Executiva (2008) Mais saúde: direito de todos: 2008-2011. Brasília: Editora do Ministério da Saúde.

Centers for Disease Control and Prevention (CDC) (2008) Invasive pneumococcal disease in children 5 years after conjugate vaccine introduction —eight states, 1998-2005. MMWR Morb Mortal Wkly Rep 57:144-148.

Clinical Laboratory Standards Institute (CLSI) (2007) Performance standards for antimicrobial susceptibility testing: 17th informational supplement, approved standard (M100-S17). Wayne, PA: CLSI.

Carvalho M da G, Pimenta FC, Gertz Jr RE, Joshi HH, Trujillo AA, Keys LE, Findley J, Moura IS, Park IH, Hollingshead SK, Pilishvili T, Whitney CG, Nahm MH, Beall BW (2009) PCR-based quantitation and clonal diversity of the current prevalent invasive serogroup 6 pneumococcal serotype, 6C, in the United States in 1999 and 2006 to 2007. J Clin Microbiol 47:554-559.

$\mathrm{du}$ Plessis M, von Gottberg A, Madhi SA, Hattingh O, de Gouveia L, Klugman KP (2008) Serotype 6C is associated with penicillinsusceptible meningeal infections in human immunodeficiency virus (HIV)-infected adults among invasive pneumococcal isolates previously identified as serotype 6A in South Africa. Int J Antimicrob Agents 32 (Suppl 1):S66-S70.

Enright MC, Spratt BG (1998) A multilocus sequence typing scheme for Streptococcus pneumoniae: identification of clones associated with serious invasive disease. Microbiology 144(Pt 11):3049-3060.

Granat SM, Mia Z, Ollgren J, Herva E, Das M, Piirainen L, Auranen K, Makela PH (2007) Longitudinal study on pneumococcal carriage during the first year of life in Bangladesh. Pediatr Infect Dis J 26:319-324.

Hausdorff WP, Bryant J, Paradiso PR, Siber GR (2000) Which pneumococcal serogroups cause the most invasive disease: implications for conjugate vaccine formulation and use, part I. Clin Infect Dis 30:100-121.

Hicks LA, Harrison LH, Flannery B, Hadler JL, Schaffner W, Craig AS, Jackson D, Thomas A, Beall B, Lynfield R, Reingold A, Farley MM, Whitney CG (2007) Incidence of pneumococcal disease due to nonpneumococcal conjugate vaccine (PCV7) serotypes in the United States during the era of widespread PCV7 vaccination, 1998-2004. J Infect Dis 196:1346-1354.
Jacobs MR, Bajaksouzian S, Bonomo RA, Good CE, Windau AR, Hujer AM, Massire C, Melton R, Blyn LB, Ecker DJ, Sampath R (2009) Occurrence, distribution, and origins of Streptococcus pneumoniae serotype 6C, a recently recognized serotype. J Clin Microbiol 47: 64-72.

Kadioglu A, Weiser JN, Paton JC, Andrew PW (2008) The role of Streptococcus pneumoniae virulence factors in host respiratory colonization and disease. Nat Rev Microbiol 6:288-301.

McEllistrem MC, Stout JE, Harrison LH (2000) Simplified protocol for pulsed-field gel electrophoresis analysis of Streptococcus pneumoniae. J Clin Microbiol 38:351-353.

Moore MR, Gertz Jr RE, Woodbury RL, Barkocy-Gallagher GA, Schaffner W, Lexau C, Gershman K, Reingold A, Farley M, Harrison LH, Hadler JL, Bennett NM, Thomas AR, McGee L, Pilishvili T, Brueggemann AB, Whitney CG, Jorgensen JH, Beall B (2008) Population snapshot of emergent Streptococcus pneumoniae serotype 19A in the United States, 2005. J Infect Dis 197:1016-1027.

Nunes S, Valente C, Sa-Leao R, de Lencastre H (2009) Temporal trends and molecular epidemiology of recently described serotype 6C of Streptococcus pneumoniae. J Clin Microbiol 47:472-474.

Pai R, Gertz RE, Whitney CG, Beall B (2005) Clonal association between Streptococcus pneumoniae serotype 23A, circulating within the United States, and an internationally dispersed clone of serotype 23F. J Clin Microbiol 43:5440-5444.

Park IH, Park S, Hollingshead SK, Nahm MH (2007a) Genetic basis for the new pneumococcal serotype, 6C. Infect Immun 75:4482-4489.

Park IH, Pritchard DG, Cartee R, Brandao A, Brandileone MC, Nahm MH (2007b) Discovery of a new capsular serotype (6C) within serogroup 6 of Streptococcus pneumoniae. J Clin Microbiol 45:1225-1233.

Park IH, Moore MR, Treanor JJ, Pelton SI, Pilishvili T, Beall B, Shelly MA, Mahon BE, Nahm MH (2008) Differential effects of pneumococcal vaccines against serotypes 6A and 6C. J Infect Dis 198:1818-1822.

Reis JN, Palma T, Ribeiro GS, Pinheiro RM, Ribeiro CT, Cordeiro SM, da Silva Filho HP, Moschioni M, Thompson TA, Spratt B, Riley LW, Barocchi MA, Reis MG, Ko AI (2008) Transmission of Streptococcus pneumoniae in an urban slum community. J Infect 57:204-213.

Tenover FC, Arbeit RD, Goering RV, Mickelsen PA, Murray BE, Persing DH, Swaminathan B (1995) Interpreting chromosomal DNA restriction patterns produced by pulsed-field gel electrophoresis: criteria for bacterial strain typing. J Clin Microbiol 33:2233-2239.

World Health Organization (WHO) (2007) Pneumococcal conjugate vaccine for childhood immunization-WHO position paper. Wkly Epidemiol Rec 82:93-104. 